\title{
El teatro de Jovellanos. Ediciones, traducciones y bibliografía
}

Noelia García Díaz

Instituto Feijoo de Estudios del Siglo XVIII

(Universidad de Oviedo) 
Resumen: Relación de las ediciones del teatro de Jovellanos, así como las de su traducción de la Iphigenia de Racine, las traducciones de sus dos obras y la bibliografía sobre su teatro.

Palabras clave: Jovellanos,Traducción, Teatro, Bibliografía. 
En las páginas que siguen he reunido las ediciones que se han hecho de las obras de teatro de Jovellanos, El delincuente honrado y Pelayo (Munuza), diferenciando las exentas — con sus dos versiones_ y las compartidas, así como las de su traducción, recientemente recuperada, de la Iphigenia de Racine.

En la trascripción de los títulos he respetado la ortografía, la acentuación y la puntuación. No todas las ediciones he podido tenerlas a la vista, pero he considerado oportuno ofrecer las noticias que de ellas se ha dado indicando la fuente.

Incluyo también las traducciones de sus dos obras, indexándolas por el nombre del traductor. En aquellos casos en que no las he localizado, ofrezco las noticias de que dispongo.

\section{Ediciones}

\section{I.1. Exentas}

El delincuente honrado

\section{Primera versión}

Tragi-comedia en prosa. El delinquente honrado. Caso sucedido en la Ciudad de Segovia en el año de 1738, [s.l.], [s.a.]. [Según Piero Menarini (ed., Il Torquato o sia l'onorato delincuente (El delincuente honrado), Bologna, Il Capitello del Sole, (col. Iberica, Testi e Studi Spanici, 13, sezione: Settecento), 2008, pág. 6) se trata de una versión «primitiva» muy incorrecta, «probablemente basada en una copia que parece ser de actor, no de autor. La datación es dudosa: podría tratarse de la de Madrid de 1780, citada por Gaillard»].

Tragi-comedia: El delinquente honrado. Caso sucedido en la Ciudad de Segovia en el año de 1738, Barcelona, Juan Francisco Piferrer. [Russell P. Sebold (ed., El delincuente honrado, Madrid, Cátedra, 2008, pág. 87) da como fecha el decenio de 1770; Menarini (pág. 7) la sitúa entre 1793 y 1794]. 
Tragi-comedia en prosa: El delinquente honrado. Caso sucedido en la Ciudad de Segovia en el Año de 1738, Barcelona, Carlos Gibert y Tutó, Impresor y Librero, [decenio de 1770, Sebold, pág. 87; h. 1782, Antonio Palau y Dulcet, Manual del Librero Hipanoamericano, VII, Barcelona, 1954, pág. 214 b y José Simón Díaz, Manual de bibliografía de la literatura española, Madrid, 1980, pág. 569; h. 1785, Julio Somoza, Inventario de un jovellanista, Madrid, Sucesores de Rivadeneyra, 1901, pág. 60].

Hay otra edición posterior de Gibert y Tutó «prácticamente igual, pero que se diferencia, entre otras cosas, porque no utiliza nunca la $s$ alta» [José Miguel Caso González (ed.), Obras Completas. Tomo I: Obras Literarias, Oviedo, Centro de Estudios del Siglo XVIII-Ayuntamiento de Gijón, 1984, pág. 471].

Tragicomedia: El delinquente honrado. Caso sucedido en la Ciudad de Segovia en el año de 1738, Barcelona, Agustín Roca, [s.a.]. [Francisco Aguilar Piñal, Bibliografía de autores españoles del siglo XVIII, Consejo Superior de Investigaciones Científicas, Madrid, 1986, t. IV, n. ${ }^{\circ}$ 5166].

Tragicomedia: El delinquente honrado. Caso sucedido en la Ciudad de Segovia en el año de 1738, Barcelona, Viuda de Piferrer, [¿anterior a 1787?], núm. 1. [Para Menarini (pág. 6), la existencia de esta edición queda demostrada «por el frontispicio de la N. 10, de la misma Viuda de Piferrer, en el que se aclara: "Corregida y enmendada en esta segunda impresión". Si la afirmación es exacta, debería entonces tratarse de una versión todavía incorrecta, y por lo tanto impresa antes de la princeps, que es la única fuente para "corregir y enmendar"»].

Tragicomedia: El delinquente honrado. Caso sucedido en la Ciudad de Segovia en el año de 1738, Barcelona, Viuda de Piferrer, [s.a.]. [Según Menarini se trata de una edición posterior a 1787: «Si realmente se trata de una impresión "corregida y enmendada" ello no es posible sino hasta 1787. Eulalia, viuda de Tomás Piferrer, continuó la actividad de su esposo después de la muerte de éste (1775). En efecto, en dos relaciones de los impresores que actuaban en Barcelona en 1780 y en 1788, aparece la empresa bajo la razón social de la Viuda de Piferrer. Debería, por lo tanto, ser anterior a la edición del hijo de Eulalia Piferrer, es decir, Juan Francisco»].

Segunda versión

El Delinquente honrado, Comedia en prosa. Publícala D. Toribio Suárez de Langreo, Madrid, 2. , 3. ${ }^{\mathrm{a}}, 4 .^{\mathrm{a}}$ y 5. ${ }^{\mathrm{a}}$ eds. [Menarini (pág. 7) establece la existencia de estas cuatro ediciones por conjetura «por así decirlo, matemática. En 
efecto, en 1793 se vendía en la Librería Quiroga (y quizá incluso se había editado) la "sexta edición", mientras que en 1803 en la Imprenta de García se editó la "octava edición”. Es evidente que la numeración de estas ocho impresiones empieza a partir de la princeps de 1787, en primer lugar porque Jovellanos no conocía las anteriores (efectivamente sólo cita una de ellas) y, en segundo lugar, porque nunca permitiría iniciar la numeración con la que consideraba desfigurada»].

El Delinquente honrado, Comedia en prosa. Publícala D. Toribio Suárez de Langreo, Madrid, Viuda de Ibarra, Hijos y Compañía, 1787. [Edición al cuidado de Jovellanos. Contiene la «Advertencia del editor», un «Apéndice» con dos cartas de Eymar de Valchrétien y otra de Jovellanos, más la «Advertencia» del impresor].

El Delinquente honrado, Comedia en prosa. Publícala D. Toribio Suárez de Langreo, Fielmente adicionada corregida y enmendada en esta sexta impresión, Madrid, 1793. [Aguilar Piñal, n. ${ }^{\circ}$ 5165; Menarini (pág. 7) señala una edición en Madrid, Librería Quiroga, 1793, que, dice, podría ser la misma que menciona Aguilar Piñal.].

El Delinquente honrado, Comedia en prosa en cinco actos. Publícala Don Toribio Suárez de Langreo, Madrid, Librería de Quiroga, 1803, 7. a ed.

El Delinquente honrado, Comedia en prosa en cinco actos. Publícala Don Toribio Suárez de Langréo [sic], Madrid, García y Compañía, 1803, 8. a ed.

El Delinquente honrado, Comedia en prosa en cinco actos. Publícala D. Toribio Suárez de Langreo, Barcelona, 1806, 1818. [Somoza, pág. 61].

El Delinquente honrado, Madrid, 1814. [John Dowling, «La sincronía de El delincuente honrado de Jovellanos y Las noches lúgubres de Cadalso», Nueva Revista de Filología Hispánica, t. XXXIII, núm. 1, 1984, Centro de Estudios Lingüísticos y Literarios, El Colegio de México, p. 220].

El Delincuente honrado, Valencia, 1815. [Aguilar Piñal, n. $\left.{ }^{\circ} 5169\right]$.

El delincuente honrado. Comedia en cinco actos, en prosa. Publícala D. Toribio Suárez de Langreo. Fielmente corregida, adicionada y enmendada en esta impresión, Valencia, imp. Ildefonso Mompié, 1818, 1822.

El delincuente honrado. Comedia en cinco actos en prosa. Publícala D. Toribio Suárez de Langreo, Valencia, 1822. [Es distinta de la anteriormente reseñada, Caso González, pág. 476].

El Delinquente honrado, Comedia en cinco actos en prosa. Publícala D. Toribio Suárez de Langreo, Burdeos, imp. Lavalle joven, 1818, 1827. [Palau, pág. 214 b y Sebold, pág. 88]. 
Burdeos, imp. de Pedro Beaume, 1827. [Sebold, pág. 88].

El Delinquente honrado, Comedia en cinco actos en prosa. Publícala D. Toribio Suárez de Langreo, Habana, imp. de R. Oliva, 1840. [Somoza, pág. 61 y Sebold, pág. 88].

El delincuente honrado: Comedia en cinco actos y en prosa, fielmente corregida, adicionada y enmendada en esta impresión, Madrid, imp. y librería de la Viuda e Hijos de José Cuesta, 1863.

Barcelona, Manero, 1864. [Palau, pág. 214 b y Sebold, pág. 88].

El delincuente honrado, Valencia, Terraga, Alienza y Compañía Editores, 1877, 1878. [Palau cita la edición de 1877, a la que Sebold añade la de 1878, también citada por Somoza, pág. 61].

El delincuente honrado: Comedia por Don Gaspar Melchor de Jovellanos, Gijón, Imprenta y Litografía de Torre y Compañía, 1891. [Editada para conmemorar la inauguración de la estatua de Jovellanos en Gijón, 6 de agosto de 1891].

El delincuente honrado, comedia edited with introduction, notes, exercises and vocabulary by H. Chonon Berkowitz and Samuel A. Wofsy, Nueva York y Londres, The Century Co., 1927.

El delincuente honrado, Madrid, Compañía Iberoamericana de Publicaciones, [s. a.], [h. 1930]. [Sebold, pág. 88].

Madrid, Taurus, 1979, 1993. [Sebold, pág. 88].

El delincuente honrado, Barcelona, Linkgua ediciones, 2004, 2007.

El delincuente honrado, ed. de Russell P. SEвоLd, Madrid, Cátedra (Letras Hispánicas, 612), 2008.

\section{Pelayo o Munuza}

Primera versión

Pelayo. Tragedia en cinco actos, Madrid, 1814. [Según Palau (pág. 216) se reimprimió furtivamente en Barcelona bajo el título de Munuza, [s.a.]. Luego en Gijón, Torre y C.a , 1891. Somoza señala que se reimprimió con el nombre de Munuza, sin prólogo ni notas y con muchos versos alterados, pág. 58; también consigna la edición furtiva de Barcelona, pág. 59].

Pelayo. Tragedia por don Gaspar Melchor de Jovellanos, Gijón, Imprenta y Litografía de Torre y Compañía, 1891. [Editada para conmemorar la inau- 
guración de la estatua de Jovellanos en Gijón, 6 de agosto de 1891; es reimpresión de la anterior, Palau, pág. 216].

Segunda versión (como consecuencia del estreno en Madrid):

Munuza. Tragedia en cinco actos, Madrid, Librería de Castillo, [s.a.]. [Anunciada en la Gaceta de Madrid el 9 de octubre de 1792].

Munuza. Tragedia en cinco actos, Madrid, [1792]. [Aguilar Piñal, n. ${ }^{\circ}$ 5157].

Munuza. Tragedia en cinco actos, Barcelona, Juan Francisco Piferrer, Impresor de S. M., [s.a.].

\section{Iphigenia}

Iphigenia. Tragedia escrita en Franz[é]s por Juan Racine y traducida al Español por D[o]n Gaspar de Jove y Llanos, Alcalde de la Quadra de la R[ea]l Aud[ienci]a de Sevilla. Para el uso del Theatro de los Sitios R[eale]s. Año de 1769, ed. facsímil digital en 〈http://www.ifesxviii.es/ifigenia.php〉, Oviedo, Instituto Feijoo de Estudios del Siglo XVIII, 2007.

Iphigenia. Tragedia escrita en Francés por Juan Racine y traducida al español por don Gaspar de Jove y Llanos, Alcalde de la Quadra de la Real Audiencia de Sevilla. Año de 1769, Jesús Menéndez Peláez (coord.), Editio Princeps, Gijón, Fundación Foro Jovellanos del Principado de Asturias y Cajastur (Cuadernos de Investigación, Monografías II), 2007.

Edición crítica e introducción de René Andioc, en Cuadernos de Estudios del Siglo XVIII. La "Ifigenia" de Jovellanos, Inmaculada UrZainqui (coord.), número monográfico (n. $\left.{ }^{\circ} 20\right), 2010$.

\section{I.2. Compartidas}

\section{El delincuente honrado}

Noches lúgubres, por el Coronel D. José Cadalso, seguidas del Delinqüente honrado, drama en prosa por D. Melchor Gaspar de Jovellanos, Burdeos, imp. Lawalle joven, 1818 [2. ${ }^{\mathrm{a}}$ ed., Lawalle Joven y Sobrino, 1823].

Noches lúgubres por D. José Cadalso. Nueva edición a la que se ha añadido El delincuente honrado, drama en cinco actos, Burdeos, imp. de Pedro Beaume, 1827. [Dowling, p. 221]. 
Noches lúgubres por el Coronel D. José Cadalso, seguidas del Delincuente honrado, drama en prosa, por D. Melchor Gaspar de Jovellanos, Nueva York, Lanuza, Mendía y C. a , 1829.

Colección de varias obras en prosa y verso del Excmo. Sr. D. Gaspar Melchor de Jovellanos, adicionadas con algunas notas Por D. R[amón] M[aría] C[añedo], Madrid, imp. León Amarita, 1832, t. VII, págs. 3-114.

Obras del Excelentísimo Señor don Gaspar Melchor de Jovellanos. Ilustradas por D. Venceslao de Linares y Pacheco, t. II, Barcelona, imp. de Francisco Oliva, 1839, págs. V-XIX y 1-59.

Tesoro del teatro español, desde su origen (año de 1356) hasta nuestros días, arreglado y dividido en cuatro partes por D. Eugenio de Ochoa, París, Baudry, 1838, t. V, págs. 430-454.

Obras de Don Gaspar Melchor de Jovellanos, Madrid, Establecimiento Tipográfico de D. F. de P. Mellado, 1846, t. V, págs. 5-79.

Obras de Don Gaspar Melchor de Jovellanos, Logroño-Zaragoza, imp. Domingo Ruiz, 1846, t. III, págs. 5-106. [Es reproducción de la anterior].

Obras del Excelentísimo Señor D. Gaspar Melchor de Jovellanos. Ilustradas por D. Venceslao de Linares y Pacheco, Barcelona, imp. Francisco Oliva, 1839, t. II, págs. V-XIX y 1-59. [Hay una 2. ${ }^{a}$ edición (Barcelona, Librería de José Ribet, 1857), que parece nueva tirada de la anterior con cambio de portada, Caso González, pág. 476].

Obras publicadas e inéditas de D. Gaspar Melchor de Jovellanos. Colección hecha e ilustrada por D. Cándido Nocedal, Madrid, (Biblioteca de Autores Españoles), 1858, vol. 46, págs. 77-100. [Hay diversas reediciones 1898, 1910, 1951, 1952, 1963, 1969].

El delincuente honrado y varias obras, Madrid, imp. de la Biblioteca Universal, (Biblioteca Universal: colección de los mejores autores antiguos y modernos), t. 61, 1880, págs. 5-98.

El delincuente honrado y varias obras, Madrid, Librería de Perlado Páez y C. a , (imp. Sucesores de Hernando), (Biblioteca Universal: colección de los mejores autores antiguos y modernos), t. 61, 1903 [reed. 1917 y 1926].

Jovellanos. Colección de obras escogidas de tan esclarecido autor, precedidas de unos apuntes biográficos de J[uan] A[lonso] del R[eal], Barcelona, (Biblioteca Amena e Instructiva), 1884, págs. 26-76.

Obras escogidas de D. Gaspar Melchor de Jovellanos, Barcelona (Biblioteca Clásica Española), Daniel Cortezo y C. a, t. III, 1884 [reed. 1886], págs. 269-335. 
El delincuente honrado. Editado con La discreta y la boba, sainete de Ramón de la Cruz, Madrid, imp. particular La Última Moda, 1909, págs. 1-26 [y 1908, Sebold, p. 88].

Obras selectas. Prólogo de Ignacio Bauer, Madrid, Iberoamericana (CIAP) (Bibliotecas Populares Cervantes, Las Cien Mejores Obras de la Literatura Española, vol. 29), [1928?].

Catena, Elena (ed.), Teatro español del siglo XVIII (La Raquel, El sí de las niñas, El delincuente honrado, La casa de Tócame Roque), Madrid, La Muralla, 1969, págs. 269-370.

Johnson, Jerry L. (ed.), Teatro español del siglo XVIII. Antología, Barcelona, Bruguera, 1972, págs. 733-820.

Caso González, José Miguel (ed.), Obras Completas. Tomo I: Obras Literarias, Oviedo, Centro de Estudios del Siglo XVIII-Ayuntamiento de Gijón, 1984, págs. 467-565. [El texto en la Biblioteca Virtual Cervantes.]

- (ed.), Escritos literarios, (Clásicos Castellanos, serie nueva, 7), Madrid, Espasa Calpe, 1987, págs. 343-458.

Polt, John H. R. (ed.), Poesía. Teatro. Prosa literaria, Madrid, Clásicos Taurus, 10, 1993, págs 223-288.

Domenech Rico, Fernando (ed.), La comedia lacrimosa española. Gaspar Melchor de Jovellanos "El delincuente honrado», Luciano Francisco Comella «La Cecilia», Leandro Fernández de Moratín «El viejo y la niña», Madrid, Fundamentos, 2006, págs. 37-99.

\section{Pelayo o Munuza}

Colección de las mejores comedias nuevas que se van representando en los teatros de esta corte que comprenden las representadas en el año de 1792, Madrid, imp. de Ramón Ruiz, [s.a.], t. V, pág. 39 y ss.

Colección de varias obras en prosa y verso del Excmo. Señor don Gaspar Melchor de Jovellanos: adicionada con algunas notas por don R[amón] M[aría] C[añedo], Madrid, León Amarita, 1832, t. VI, págs. 289-422. [Las ediciones posteriores a 1832 han seguido el texto de Cañedo].

Obras del Excelentísimo Señor don Gaspar Melchor de Jovellanos. Ilustradas por don Venceslao de Linares y Pacheco, Barcelona, imp. de don Francisco

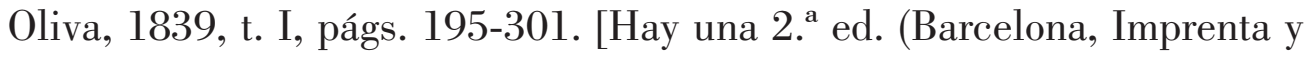


Librería de José Ribet, 1857), que parece nueva tirada de la edición de 1839].

Obras de don Gaspar Melchor de Jovellanos, Madrid, Establecimiento Tipográfico de D. F. de P. Mellado, 1846, t. IV págs. 391-503.

Obras de Don Gaspar Melchor de Jovellanos, Logroño [Zaragoza], imp. Domingo Ruiz, 1846, t. II, págs. 5-141.

Obras publicadas e inéditas de don Gaspar Melchor de Jovellanos. Colección hecha e ilustrada por don Cándido Nocedal, Madrid, Rivadeneira (Biblioteca de Autores Españoles, vol. 46), 1858, págs. 51-76. [Hay diversas reediciones 1898, 1910, 1951, 1952, 1963, 1969].

Ley Agraria. Pelayo, Madrid, Librería y Casa Editorial Hernando (Biblioteca Universal, Colección de los Mejores Autores Antiguos y Modernos, Nacionales y Extranjeros, 81), 1927.

Caso González, José Miguel (ed.), Obras Completas. Tomo I: Obras Literarias, Oviedo, Centro de Estudios del Siglo XVIII-Ayuntamiento de Gijón, 1984, págs. 351-466.

Potr, John H. R. (ed.), Poesía. Teatro. Prosa literaria, Madrid, Clásicos Taurus, 10, 1993, págs. 133-222.

\section{Traducciones}

Francés

D’Eymar de Valchrétien (o Walchrétien), Jean-François-Ánge, Le coupable vertueux, Marsella, 1777. [Somoza, Inventario, pág. 61]. Existía copia, de letra del traductor, en el volumen XIII de los manuscritos de la Biblioteca del Instituto de Jovellanos, y otra idéntica, de letra distinta, en el vol. XIV [Julio Soмоza, Catálogo de manuscritos e impresos notables del Instituto de Jovellanos, Oviedo, 1883, págs. 38 y 42]. Según afirma el propio Valchrétien en su segunda carta a Jovellanos, de 24 de octubre de 1777, esta traducción fue estrenada con mucho éxito en el Teatro Francés de Cádiz el día anterior, 23 de octubre [El delincuente honrado, Madrid, Viuda de Ibarra, 1787, Apéndice III].

Fenouillot de Falbières (o Falbaire), Charles-Georges, L'Honnéte criminel, 1767. Según Eugenio de Оснол (Tesoro del Teatro Español, París, 1838, 
t. V, pág. 430), Fenouillot, acusado en Francia de que su L'Honnête criminel era una imitación o plagio de El delincuente, tradujo esta última obra literalmente al francés para probar que la suya era original. Somoza (Inventario, pág. 61) se limita a señalarla.

\section{Alemán}

Leonini, Joseph, Der edle Verbrecher, Berlín/Grätz, Lagarde, 1796.

Distinta de ambas debe ser la que dice haber hecho José GARcía León y PizARRo (Memorias para la vida del Excmo. Sr. D. José García León y Pizarro, Madrid, 1894, t. I, pág. 57) y se representaba en Viena con gran éxito: «Me perfeccioné en el alemán y me instruí en la literatura del país, de tal manera que emprendí la traducción al alemán del Delincuente honrado, que se representa en aquellos teatros, y revivió en aquel país el gusto por nuestro teatro, en términos que, fomentado después por las excelentes traducciones de Schlegel y otros, se ha creado una secta, por decirlo así, de aficionados a él en contraposición al despótico de Francia».

\section{Italiano}

Avelloni, Franceso Maria, Il Delinquente Onorato, Napoli, 1778 [y Roma, 1783]. Según Joseph G. Fucilla (Relaciones Hispanoitalianas, Madrid, Consejo Superior de Investigaciones Científicas, 1953, pág. 200), se trata de una adaptación de la comedia de Jovellanos.

Saverio Peirolón, Francisco, Il Torquato o sia l'onorato delinquente. Tragedia urbana di lieto fine. Tradotta dall'idioma Spagnuolo dall'Abb. D. Francesco Saverio Peirolón, [s.a.] [pero anterior a 1791].

Frendo, Cristoforo, Il delinquente onorato tragicommedia tradotta dallo spagnuolo da Cristoforo Frendo, Malta, 1791. [No mencionada por nadie. Hay ejemplar en la Biblioteca Nacional de Malta].

GARCía, Antonio, Il reo per onore, osia il delinquente onorato, commedia urbana in cinque atti, tradotta dal castigliano dal Signor abbate D. Antonio Garzia, Venezia, Andrea Santini, 1807.

Pomares, Francesco, Tragi-commedia in prosa Il delinquente onorato. Caso accaduto in Segovia, città della Castiglia vecchia nella Spagna l'anno 1738. Tradotta dall'idioma spagnuolo nell'italiano dall'abate D. Francesco Poma- 
res spagnuolo valenciano in Roma l'anno 1815, Roma, Carlo Mordacchini, 1816.

Madernino Gresti, Antonio, Don Torquato Ramirez. Dramma in cinque atti del signor Tovellanos [sic]; tradotto dallo spagnuolo da Antonio Madernino Gresti, Accademico Agiato, Milano, Placido Maria Visaj, 1844.

Gómez de Terán, Francisco, Il delinquente onorato. Dramma in 5 atti del Signor D. Gaspare Melchiore de Iovellanos, versione dallo spagnuolo di Francesco Gómez de Terán, en Teatro moderno spagnuolo ovvero Collana di produzioni teatrali di Moderni autori spagnuoli scelte e tradotte in idioma italiano da Francesco Gómez de Terán, Napoli, Stabilimento tipografico dell'Ancora, 1848.

Saverio Peirolón, Francisco, Il Torquato o sia l'onorato delincuente (El delincuente honrado), Piero Menarini (ed.), Bologna, Il Capitello del Sole, (col. Iberica, Testi e Studi Spanici, 13, sezione: Settecento), 2008. [Incluye un estudio sobre las ediciones, adaptaciones y traducciones].

Inglés

Dice Jovellanos en la Advertencia de la edición de 1787 de El delincuente honrado: «[...] si hay fe en las relaciones de viajes, en 1779 estaba también traducido al inglés, y admitido ya en los teatros de la Gran Bretaña».

\section{Bibliografía}

Aguilar Piñal, Francisco, Sevilla y el teatro en el siglo XVIII, Oviedo, Cátedra Feijoo, 1974.

— «Los escritos literarios de Jovellanos», en Ínsula, n. ${ }^{\circ}$ 492, 1987, pág. 6.

AnDIOc, René, Teatro y sociedad en el Madrid del siglo XVIII, Valencia y Madrid, Fundación Juan March y Castalia, 1976.

- y Coulon, Mireille, Cartelera teatral madrileña del siglo XVIII (1708-1808), Toulouse, Presses Universitaires du Mirail, 1996, 2 vols [reed. 2008].

— «El extraño caso del estreno de Munuza», en Hommage à François Lopez. Bulletin Hispanique, n. ${ }^{\circ}$ 1, (juin 2002), págs. 70-100; reimpreso en Del siglo XVIII al XIX. Estudios histórico-literarios, Zaragoza, Prensas Universitarias de Zaragoza, 2005, págs. 441-481. 
— «Introducción», en Cuadernos de Estudios del Siglo XVIII. La "Ifigenia" de Jovellanos, Inmaculada UrZainqui (coord.), número monográfico (n. $\left.{ }^{\circ} 20\right)$, 2010.

Balbín N. de Prado, Rafael, Tres autores neoclásicos: Cadalso, Jovellanos y Leandro Fernández de Moratín, Madrid, Cincel (Cuadernos de Estudio, serie Literatura, 12), 1981.

BEVERLEY, John, «The dramatic logic of El delincuente honrado», en Revista Hispánica Moderna, n. ${ }^{\circ}$ XXXVII, 1972-1973, págs. 155-161.

Cañas Murillo, Jesús, La comedia sentimental, género español del siglo XVIII, Cáceres, Universidad de Extremadura (Trabajos del Departamento de Filología Hispánica, 14), 1994.

Cardenal de Iracheta, Manuel, «Jovellanos, autor dramático», en $S i ́$, suplemento semanal del diario Arriba, número homenaje a Jovellanos en el bicentenario de su nacimiento, Madrid, año III, 9 de enero de 1944, págs. 8-9.

CARnero, Guillermo, «Una nueva fórmula dramática: la comedia sentimental», en La cara oscura del Siglo de las Luces, Madrid, Fundación Juan March y Cátedra, 1983, págs. 39-65.

Coronas GonzÁlez, Santos Manuel, «Magistrados y poetas en la España de la Ilustración», en Cuadernos de Estudio del Siglo XVIII, n ${ }^{\text {os }}$ 12-13 (20022003), págs. 21-46.

Casalduero, Joaquín, «El reló y la ley de las tres unidades (Jovellanos y Moratín)», en Cuadernos Americanos, n. ${ }^{\circ}$ 159, 1959, págs. 167-178.

Caso GonzÁlez, José Miguel, «El delincuente honrado, drama sentimental», en Archivum, Oviedo, n. ${ }^{\circ}$ XIV, 1964, págs. 103-133.

- «El comienzo de la Reconquista en tres obras dramáticas. (Ensayo sobre estilos de la segunda mitad del XVIII)», en El padre Feijoo y su siglo, Cuadernos de la Cátedra Feijoo, n. ${ }^{\circ}$ 18, vol. III, 1966, págs. 499-509.

- «Rococó, prerromanticismo y neoclasicismo en el teatro español del siglo XVIII. (El delincuente honrado de Jovellanos)», en Los conceptos de rococó, neoclasicismo y prerromanticismo en la literatura del siglo XVIII, Cuadernos de la Cátedra Feijoo, n. ${ }^{\circ}$ 22, 1970, págs. 7-29.

- «El delincuente honrado, drama sentimental», en La poética de Jovellanos, Madrid, Prensa Española (El Soto, 18), 1972, págs. 193-234.

- «La justicia, los jueces y la libertad humana según Jovellanos», en Libro del bicentenario del Colegio de Abogados, Oviedo, 1975, págs. 45-47. 
— «El delincuente honrado, drama sentimental», en Francisco Rico (ed.), Historia y Crítica de la Literatura Española. Ilustración y Neoclasicismo, Barcelona, Crítica y Grijalbo, 1983, t. IV, págs. 400-407.

Caso Machicado, María Teresa, «A modo de prólogo. ¿Jovellanos autor de la traducción de Ifigenia?», en Iphigenia. Tragedia escrita en Francés por Juan Racine y traducida al Español por Don Gaspar de Jove y Llanos [...], Gijón, Fundación Foro Jovellanos del Principado de Asturias y Cajastur (Cuadernos de Investigación, Monografías II), 2007, págs. 19-23.

Ceán Bermúdez, Juan Agustín, Memorias para la vida del Excmo. Sr. don Gaspar Melchor de Jovellanos y noticias analíticas de sus obras, Madrid, imp. que fue de Fuentenebro, 1814 [1820]. [Hay ed. facsímil, con prólogo de Javier Barón Thaidigsmann, Gijón, Silverio Cañada (ed.), 1989.]

CEDEÑo, Aristófanes, «La función teatral de la reforma social en El delincuente honrado», en Dieciocho, (Charlottesville, The University of Virginia), XXIV, n. ${ }^{\circ} 2,2001$, págs. 279-296.

CHIERICI, Saveria, Una traduzione italiana inedita de «El delincuente honrado» di Jovellanos, Tesi di Laurea, relatore: prof. Piero Menarini, a. a. 1997-1998.

CipolLini, Marco, «Il tema dell'onore tra opinione del pubblico e opinione pubblica. (Riforma del teatro e riforma della giustizia in Jovellanos)», en Cesare Giovanni Battista (ed. e introd.), La festa teatrale hipánica. Atti del Convegno di Studi, 1-3 dicembre, 1994, Napoli, Dipartamento di Studi Letterari e Linguistici dell'Occidente, Instituto Universitario Orientale, 1995, págs. 240-261.

Coe, Ada M., Catálogo bibliográfico y crítico de las comedias anunciadas en los periódicos de Madrid desde 1661 hasta 1819, Baltimore (Maryland), The Johns Hopkins Press, 1935, págs. 233-235.

Соoк, John A., The Neo-Classic Drama in Spain. Theory and Practice, Dallas, Southern Methodist University Press, 1959. [Reimpresión, Westport (Connecticut), Greenwood Press Publishers, 1974].

Dowling, John, «La sincronía de El delincuente honrado de Jovellanos y las Noches lúgubres de Cadalso», en Nueva Revista de Filología Hispánica, XXXIII, (1984), págs. 218-223.

— «Vida azarosa y drama llorón de Pablo de Olavide y Gaspar de Jovellanos: agonistas de la reforma del teatro español», en Michigan Romance Studies. (Pen and Peruke: Spanish Literature of the Eighteenth Century, Monroe Z. Hafter (ed.)), n. ${ }^{\circ} 12,1992$, págs. 1-24. 
— «El teatro del siglo XVIII (II)», en Guillermo Carnero (coord.), Historia de la literatura española. Siglo XVIII, t. I, Madrid, Espasa-Calpe, 1995, págs. 413-485.

Eloesser, Arthur, Der bürgerliche Drama, Seine Geschichte im 18 und 19 Jarhrhundert, Slatkine, 1970 [1. 'ed., Berlín, Hertz, 1898].

Fabbri, Maurizio, Gareldi, Patrizia y Menarini, Piero, Finalità ideologiche e problematica letteraria in Salazar, Iriarte, Jovellanos. Tre saggi sul teatro spagnolo dell'ultimo settecento, Pisa, Editrice Libreria Goliardica (col. Studi e Testi, 44), 1974.

Fernández Cardo, José María, «De Racine a Jovellanos. Estudio de la traducción de Ifigenia», en Iphigenia. Tragedia escrita en Francés por Juan Racine y traducida al Español por Don Gaspar de Jove y Llanos [...], Gijón, Fundación Foro Jovellanos del Principado de Asturias y Cajastur (Cuadernos de Investigación, Monografías II), 2007, págs. 77-110.

Fuentes, Yvonne, «Two English Sources in Jovellanos' El delincuente honrado», en Dieciocho, (Charlottesville, The University of Virginia), XXII, n. ${ }^{\circ} 1,1999$, págs. 101-112.

- El triángulo sentimental en el drama del dieciocho (Inglaterra, Francia, España), (Problemmata literaria 47), Reichenberger, 1999.

García Garrosa, María Jesús, La retórica de las lágrimas: la comedia sentimental española, 1751-1802, Valladolid, Universidad de Valladolid y Caja de Salamanca, 1990, págs. 8 y ss., 58 y ss., 150 y ss.

— «El drama francés», en Francisco Lafarga (ed.), El teatro europeo en la España del siglo XVIII, Lérida, Universitat de Lleida, 1997, págs. 105-126.

Geneste, Paul, Estudio inédito sobre las fuentes de El delincuente honrado, reseñado por José Miguel Caso GonZÁLEZ en «Notas críticas de bibliografía jovellanista (1950-1959)», en Boletín de la Biblioteca Menéndez Pelayo, XXXVI, (1960), págs. 179-213.

Gouzien, C., Le théâtre de Jovellanos, París, Fac. Lettres, 1967. [Memoria para el Diploma de Estudios Superiores, bajo la dirección de Robert Ricard. Hay ejemplar mecanografiado en el Institut d'Études Hispaniques, París].

GuZmán Sancho, Agustín, «Conjeturas sobre la Ifigenia de Jovellanos», en Boletín Jovellanista, n. ${ }^{\text {os }}$ 7-8, 2008, págs. 93-96.

Huerta Viñas, Fernando, «Didactismo y sentimiento en el teatro de Jovellanos: una estética dramática a dos siglos de distancia», en Dieciocho, (Charlottesville, The University of Virginia), n. ${ }^{o}$ IX, 1986, págs. 164-173. 
Iglesias Villa, Manuel, «Con, de, en, sin, sobre Jovellanos y el teatro en Gijón», en El Alcázar, Madrid, 6 de junio de 1960.

— «Jovellanos y el teatro», en Voluntad, Gijón, 29 de septiembre de 1961.

— «Jovellanos y el teatro», en Voluntad, Gijón, 20 de octubre de 1961.

— «Algo más sobre Jovellanos y el teatro», en Voluntad, Gijón, 27 de octubre de 1961.

Lafarga, Francisco, «La traducción de tragedias francesas», en Cuadernos de Estudios del Siglo XVIII. La "Ifigenia" de Jovellanos, Inmaculada UrZAINQUi (coord.), número monográfico (n. $\left.{ }^{\circ} 20\right), 2010$.

Lope, Hans-Joachim, «Jovellanos und der Mythos von Covadonga. Bemerkungen zu La muerte de Munuza (1769-1772)», en Spanische Literatur. Literatur Europas. Wido Hempel zum 65. Geburtstag herausgegeben von Frank Baasner, Tübingen, Max Niemeyer Verlag, 1996, págs. 337-350.

Maestro, Jesús G., «El espacio dramático interlocutivo como modelo comparatista. Marivaux y Jovellanos», en Castilla, Valladolid, n. ${ }^{\circ}$ 19, 1994, págs. 51-71.

MarTínez Ruiz, José (Azorín), «Las ideas antiduelísticas», en Los valores literarios, Madrid, Renacimiento, 1913, págs. 139-143.

Martino, Antonia Marina, Un adattamento in versi di El delincuente honrado di Jovellanos, Tesi di Laurea, relatore: prof. Piero Menarini, a. a. 19992000.

McClelland, I. L., Spanish Drama of Pathos 1750-1808, Liverpool, Liverpool University Press, 1970. [Hay traducción en español: «Pathos» dramático en el teatro español de 1750 a 1808, Liverpool, Liverpool University Press, 1998, 2 vols. Sobre el Pelayo, vol. I, págs. 189-191; sobre El delincuente honrado, vol. II, págs. 404-423].

Meggiolaro, Debora, Il reo per onore (1807): una traduzione italiana di El delincuente honrado, Tesi di Laurea, relatore: prof. Piero Menarini, Bologna, Università di Bologna, Fac. Lettere e Filosofia, a. a. 1999-2000.

Menarini, Piero, «Una commedia “politica” dell'Illuminismo: El delincuente honrado di Jovellanos», en Maurizio Fabbri, Patrizia Gareldi y Piero Menarini (eds.), Finalità ideologiche e problematica letteraria in Salazar, Iriarte, Jovellanos, Pisa, Editrice Libreria Goliardica, 1974, págs. 93-168.

— «Tre contemporanei e il duello: Jovellanos, Iriarte, Montengón», en Guillermo Carnero (ed.), Montengón, Alicante, Caja de Ahorros Provincial de 
Alicante (El Escritor Alicantino y la Crítica, 2), 1991, págs. 159-180 [1. a edición en Spicilegio moderno 2 (1973), págs. 53-79.]

- (ed.), «La fortuna de El delincuente honrado de Jovellanos (Ediciones, adaptaciones, traducciones)», en Il Torquato o sia l'onorato delincuente (El delincuente honrado), Bologna, Il Capitello del Sole, (col. Iberica, Testi e Studi Spanici, 13, sezione: Settecento), 2008, págs. 5-25.

Menéndez Peláez, Jesús, y Menéndez Fernández, Carla, «Teatro y pedagogía: el sustrato didáctico de Ifigenia», en Iphigenia. Tragedia escrita en Francés por Juan Racine y traducida al español por don Gaspar de Jove y Llanos [...], Gijón, Fundación Foro Jovellanos del Principado de Asturias y Cajastur (Cuadernos de Investigación, Monografías II), 2007, págs. 25-62.

Olarte, Juan B., «Un inédito de Jovellanos en San Millán», en Iphigenia. Tragedia escrita en Francés por Juan Racine y traducida al español por don Gaspar de Jove y Llanos [...], Gijón, Fundación Foro Jovellanos del Principado de Asturias y Cajastur (Cuadernos de Investigación, Monografías II), 2007, págs. 63-77.

Pageaux, Daniel, «Le thème de la résistence asturienne dans la tragédie néoclassique espagnole», en Mélanges à la mémoire de Jean Sarrailh, Paris, Institut d'Études Hispaniques, t. III, 1966, págs. 235-242.

Pataky Kosove, Joan Lynne, «Jovellanos and El delincuente honrado», en The «Comedia lacrimosa» and Spanish Romantic Drama (1773-1865), Londres, Tamesis Books Limited, 1978, págs. 42-50.

Pitollet, Camile, «El delincuente honrado, de Jovellanos et L'Honnête criminel», en Bulletin de la Societé d'Études des Professeurs des Langues Méridionales, París, XXX, n. ${ }^{\circ}$ 87, 1935, págs. 19-21.

Polt, John H. R., «Jovellanos. El delincuente honrado», en Romanic Review, Nueva York, L, (1959), págs. 170-190.

- Gaspar Melchor de Jovellanos, Nueva York, Twayne, 1971.

— «Las bases teóricas de El delincuente honrado», en Historia y Crítica de la Literatura Española. Ilustración y Neoclasicismo, Barcelona, Crítica, 1983, vol. IV, págs. 407-412.

- Jovellanos. El delincuente honrado, Alicante, Biblioteca Virtual Miguel de Cervantes, 2004. 〈www.cervantesvirtual.com〉.

Qualia, Charles B., «The Vogue of Decadent French Tragedies in Spain, 17621800», en Publications of the Modern Language Association, n. ${ }^{\circ}$ 58, 1943, págs. 149-162. 
Reyes Palacios, Felipe, «La comedia lacrimosa en España y México: Jovellanos y Lizardi», en Tramoya, (Universidad Veracruzana, Rutgers University, Camden), 2. ${ }^{a}$ ép., núm. 69, octubre-diciembre de 2001, págs. 65-74.

Ríos Carratalá, Juan Antonio, «Jovellanos ante Vicente García de la Huerta», en Boletín del Instituto de Estudios Asturianos, XXXIX, (1985), págs. 335-343.

Rodrigo Mancho, Ricardo, «En torno a la Iphigenia de Racine, traducida por Jovellanos», en Stichomythia. Revista de Teatro Contemporáneo, n. ${ }^{\circ}$ 6, 2008, págs. 163-169.

Romero Ferrer, Alberto, «Un ataque a la estética de la razón. La crítica ilustrada frente a la tonadilla escénica: Jovellanos, Iriarte y Leandro Fernández de Moratín», en Cuadernos de Ilustración y Romanticismo. Revista del Grupo de Estudios del Siglo XVIII, n. . 1, (1991), págs. 105-128.

SaINZ de Robles, Federico Carlos, «Introducción a El delincuente honrado», en El teatro español, historia y antología desde sus orígenes hasta el siglo XIX, Madrid, Aguilar, 1943.

Sala Valldaura, José María, «Pelayo o La muerte de Munuza, de Gaspar Melchor de Jovellanos», en De amor y política: la tragedia neoclásica española, Madrid, Consejo Superior de Investigaciones Científicas, 2006, págs. 283-291.

— «La Ifigenia y la tragedia en el siglo XVIII», en Cuadernos de Estudios del Siglo XVIII. La "Ifigenia" de Jovellanos, Inmaculada Urzainqui (coord.), número monográfico (n. $\left.{ }^{\circ} 20\right), 2010$.

SÁnchez Blanco, Francisco J., «La teatralidad como estructura cultural en Jovellanos», en Dieciocho (Charlottesville, The University of Virginia), XIX, n. ${ }^{\circ}$ 2, 1996, págs. 285-300.

Sarrailh, Jean, "À propos du Delincuente honrado de Jovellanos», Mélanges d'études portugaises offerts à M. Georges Le Gentil, [Lisboa], Chartres, Durand e Instituto para Alta Cultura, 1949, págs. 337-351.

SEBold, Russell P., «Jovellanos, dramaturgo romántico», en Anales de Literatura Española, n. ${ }^{\circ}$ 4, 1986, págs. 415-438.

— «Jovellanos, dramaturgo romántico», en David T. Gies y Russell P. SEBold, Ilustración y neoclasicismo. Historia y crítica de la literatura española, Barcelona, Crítica, n. ${ }^{\circ}$ 4/1, 1992, págs. 180-189.

Selimov, Alexander R., «El honor, el amor y la inmortal hazaña del "Ínclito Pelayo" en tres tragedias neoclásicas», en Dieciocho, (Charlottesville, The University of Virginia), XXIII, n. ${ }^{\circ}$ 2, 2000, págs. 223-248. 
Tejerina, Belén, «El delincuente honrado de Jovellanos traducido al italiano por el jesuita Antonio García (1807)», en Revista de Historia Moderna. Anales de la Universidad de Alicante (serie monográfica: España e Italia en el Siglo XVIII), n. ${ }^{\circ}$ 16, 1997, págs. 51-68.

Tiozzo, Bon Graziamaria, Un adattamento in versi de El Delincuente honrado di Jovellanos. (Ms. 17381, B. N. di Madrid), Tesi di Laurea, relatore: prof. Piero Menarini, a. a. 2000-2001.

Tolivar Alas, Ana Cristina, Traducciones y adaptaciones españolas de Racine en el siglo XVIII, tesis doctoral inédita, bajo la dirección de José Miguel Caso González, Universidad de Oviedo, 1984.

— «Traducciones y adaptaciones españolas de Racine en el siglo XVIII», en Estudios de Investigación Franco-Española, Córdoba, Servicio de Publicaciones de la Universidad de Córdoba, n. ${ }^{\circ}$ 1, 1988, págs. 177-190.

— «El teatro de Racine en la España de los primeros Borbones», en Francisco Lafarga y Roberto Dengler (eds.), Teatro y traducción, Barcelona, Universitat Pompeu Fabra, 1995, págs. 59-70. (Traducido al francés, con el título «La réception de Racine dans l'Espagne du XVIII ${ }^{\mathrm{e}}$ siècle», en Mercedes BoIXareu y Roland Desné (dirs.), Recepción de autores franceses de la época clásica en los siglos XVIII y XIX en España y en el extranjero, Madrid, UNED, 2001, págs. 127-137).

— «Algunas consideraciones sobre la Ifigenia de Jovellanos», en Cuadernos de Estudios del Siglo XVIII. La "Ifigenia" de Jovellanos, Inmaculada URZAinQui (coord.), número monográfico (n. $\left.{ }^{\circ} 20\right), 2010$.

Toro y Durán, Ramón del, Jovellanos y la reforma del teatro español en el siglo XVIII, Gijón, imp. del Comercio, 1891.

Tovar Martín, Virginia, «Teatro y espectáculo en la corte de España en el siglo XVIII», en El Real Sitio de Aranjuez y el arte cortesano del siglo XVIII, Madrid, Comunidad de Madrid, 1987.

VITSE, Marc, «Teoría y práctica del teatro en Jovellanos: el caso de El delincuente honrado», en Cuadernos de investigación, n. ${ }^{\circ}$ 1, 2007, págs. 141-156. 